\title{
Características personológicas da susceptibilidade hipnótica - correlação entre IFP-R e HGSHS:A
}

\author{
Pâmela Luana Jácome Macêdo ${ }^{1}$ \\ Danilo Assis Pereira ${ }^{2}$
}

\begin{abstract}
RESUMO - Esta pesquisa buscou investigar a relação entre características personológicas e susceptibilidade hipnótica, usando o Inventário Fatorial de Personalidade, versão resumida (IFP-R) e a Escala de Grupo Harvard de Susceptibilidade Hipnótica, Forma A (HGSHS:A). Foram estudados 33 voluntários brasileiros, cuja média de susceptibilidade hipnótica foi de 54,92, muito próxima às encontradas nos países de comparação. Dois fatores de personalidade foram relacionados com a susceptibilidade hipnótica: uma correlação positiva com o fator persistência $(r=0,525 ; p=0,002)$ e negativa com o fator autonomia $(F=11,7 ; p$ $=0,00)$. Esta pesquisa não é conclusiva, devido ao pequeno número de participantes, e devido ao fato de ainda não termos uma escala de susceptibilidade hipnótica validada no Brasil.
\end{abstract}

Palavras-chave: hipnose, susceptibilidade, personalidade, escala.

\section{Personological characteristics of hypnotic susceptibility - correlation between IFP-R and HGSHS:A}

\begin{abstract}
This is an investigation between personological characteristics and hypnotic susceptibility, using a resumed personological inventory (IFP-R) and the Harvard Group Scale of Hypnotic Susceptibility, Form A (HGSHS:A). We studied 33 Brazilian adult volunteers. The mean of hypnotic susceptibility was 54.92 , very close to the comparison countries. Two personological factors were related to hypnotic susceptibility: a positive correlation with persistency ( $\mathrm{r}$ $=0.525 ; \mathrm{p}=0.002)$ and a negative with autonomy $(\mathrm{F}=11.7 ; \mathrm{p}=0.00)$. This research is not conclusive because of the small group, and the fact that there is no validated hypnotic scale in Brazilian population.
\end{abstract}

Key words: hypnosis, susceptibility, personality, scale.

\footnotetext{
${ }^{1}$ Graduanda em Psicologia (10 ${ }^{\circ}$. semestre) do UniCEUB. Voluntária do Programa de Iniciação Científica (PIC/UniCEUB).

${ }^{2}$ Professor de Psicologia do UniCEUB. Orientador e líder da pesquisa Hipnose e Cognição. E-mail: danilo.assis@uniceub.br Site:www.psicursos.com.br Agradecemos os profs. Robson Araújo e Ronaldo Pilatti pelas colaborações e sugestões.
}

Univ. Ci. Saúde, Brasília, v. 3, n. 2, p. 191-205, jul./dez. 2005 
Há muitas teorias que tentam explicar a natureza real da hipnose indicando que esta é desconhecida. Modelos conceituais sobre a hipnose vão surgindo e modificando-se com a evolução do mundo. Dentre eles estão: o tratamento pelo ímã (de Paracelso), o magnetismo animal (de Mesmer), o estado alterado de consciência (de Tart e Fromm), a abordagem interativa centrada no paciente (de Erickson), o paradigma multidimensional (de Barber), dentre inúmeros outros ${ }^{1}$.

Segundo o Executive Committee of the American Psychological Association, Division of Psychological Hypnosis, a hipnose pode ser descrita como um procedimento onde há a sugestão de um profissional de saúde ou pesquisador para a mudança em sensação, pensamento, comportamento ou percepção de um cliente, paciente ou participantes de pesquisas. A maioria das induções hipnóticas, sugere relaxamento, tranqüilidade e bem-estar. A hipnose é respondida de modos diferenciados pelas pessoas, algumas são muito responsivas ou sugestivas e outras menos responsivas às sugestões hipnóticas. As experiências experimentadas não são forçadas, mas as pessoas experienciam as sugestões mais facilmente por meio da hipnose. É um procedimento que pode ser usado para facilitar a terapia em alguns tratamentos como a dor, depressão, ansiedade, estresse, desordem de hábito e outros problemas psicológicos e médicos. É utilizada também em pesquisa, para se investigar mais sobre sua natureza, como seu impacto sobre a sensação, percepção, aprendizagem, memória e fisiologia, além de seu uso em ambiente clínico $^{2}$.

Quanto ao funcionamento das sugestões dentro do encéfalo, Ferreira (2003) diz que os mecanismos de atenção focalizada, resultado do funcionamento da atividade cortical frontal, e a alucinação obstrutiva, resultado do funcionamento dos sistemas corticais posteriores, moduladores das imagens mentais, são comuns a todas as sugestões hipnóticas. As pessoas com alta suscetibilidade hipnótica e com alta capacidade para apresentar alucinações têm ativadas uma região na parte anterior do giro do cíngulo, detectadas por meio da PET, e aquelas que não possuem capacidade para alucinar mostram ativação significativa no córtex auditivo de associação.

A sensação de bem-estar é usualmente envolvida durante a experiência da hipnose, havendo a percepção de que as coisas acontecem automaticamente, sem a intenção consciente. Nenhuma habilidade especial é proporcionada pela hipnose. As características psicológicas do estado hipnótico são: atenção seletiva, resposta alta à sugestão, transe lógico, dissociação, interpretação subjetiva e relaxamento ${ }^{3}$.

\footnotetext{
${ }^{1}$ FERREIRA, 2003.

${ }^{2}$ RHUE, LYNN \& KIRSCH, 1997.

${ }^{3}$ FERREIRA, 2003.
} 
Diversos pontos relacionados à ciência da hipnose são desconhecidos pelas comunidades, e geralmente a associam a um período pré-científico ${ }^{4}$. O surgimento de mitos e preconceitos a cerca da hipnose, além de não permitir a compreensão a numerosos conceitos e acontecimentos históricos, permite que conclusões sejam feitas sem que os seus princípios mais pertinentes sejam discutidos ${ }^{5}$. Para Ferreira (2003), existem muitos conceitos errados sobre a hipnose, como a expectativa de amnésia após ser hipnotizado, quem é hipnotizado apresenta vontade fraca, a hipnose é conseqüência do poder do hipnólogo, uma vez hipnotizado ficará dependente do hipnólogo, uma vez hipnotizado pode dizer ou fazer algo contra sua vontade e durante a hipnose o paciente executa todas as sugestões transmitidas.

Segundo Pascalis e cols. (2002), o termo sugestionabilidade tem sido tipicamente estudado como uma resposta conseqüente das pessoas para vários tipos de condições sugestivas, e a sugestão, caracterizada por suas condições antecedentes. Ferreira (2003) considera sugestionabilidade como respostas comportamentais aos procedimentos hipnóticos, a abertura para aceitar e responder a novas idéias e novas informações. Para Kirsch e col. (2001), a habilidade para responder sugestões imaginativas é uma característica humana normal, e seu efeito substancial aspira grande importância para a área clínica, como direciona um esforço para essa característica tão importante. Já a suscetibilidade hipnótica, capacidade hipnótica ou hipnotizabilidade, seria a habilidade que um indivíduo tem de tornar-se hipnotizado, diferindo em sua habilidade pessoal para responder sugestões. A suscetibilidade hipnótica pode ser alterada, aumentada ou diminuída, dependendo dos inúmeros tipos de instruções, como também de instruções repetidas ${ }^{6}$.

A observação de que pessoas diferem em seus níveis gerais de responsividade para procedimentos hipnóticos datam do século XVIII. Já era possível a medição da profundidade hipnótica num indivíduo por meio de escalas, no século XIX. No século XX, surgiram outras escalas, após pesquisas laboratoriais, que avaliam o grau de suscetibilidade de uma pessoa à hipnose em relação aos padrões da escala, que não mais pretendiam medir o grau de profundidade hipnótica. As escalas consistem de itens que vão aumentando o nível de dificuldade, definidos por amostra normativa do percentual de indivíduos que relatam experienciar cada item ${ }^{7}$. A avaliação da população para a construção da maioria das escalas de suscetibilidade hipnó-

${ }^{4}$ FREUD, 1888/ 1892; MARX \& HILLIX, 1978; SCHULTZ \& SCHULTZ, 1981 apud NEUBERN, 2004.

${ }^{5}$ NEUBERN, 2004.

${ }^{6}$ FERREIRA, 2003

${ }^{7}$ BENHAM, SMITH, \& NASH, 2002.

Univ. Ci. Saúde, Brasília, v. 3, n. 2, p. 191-205, jul./dez. 2005 
tica para adultos foi feita, geralmente, com estudantes de psicologia, não correspondendo, portanto, a uma amostra da população geral ${ }^{8}$.

Para que a aplicação das escalas de suscetibilidade hipnótica, criadas nos Estados Unidos da América do Norte, tenham valor para os brasileiros, é preciso que sejam validadas no Brasil. Em 1962, Weitzenhoffeer e Hilgard introduziram a terceira versão da escala de Stanford, a Stanford Hypnotic Susceptibility Scale, Form C (SHSS:C). Com a introdução de itens cognitivos mais difíceis, a SHSS:C permitiu pesquisas para diferenciar melhor os níveis de hipnotizabilidade elevada. Essa escala é considerada por muitos como o "estandarte de ouro" em pesquisas de hipnose 9. A Harvard Group Scale of Hypnotic Susceptibility, Form A (HGSHS:A) desenvolvida por Shor e Orne (1962) é provavelmente a medida mais usada para examinar a suscetibilidade hipnótica ${ }^{10}$. É uma versão de grupo da SHSS:A, que é registrada por cada sujeito, baseada num questionário, e foi normatizada usando 132 estudantes universitários em grupos de cinco à quarenta sujeitos ${ }^{11}$. Já a Waterloo - Stanford Group of Hypnotic Susceptibility, form C (WSGS), criada por Bowers (1998), é um outro método padronizado para avaliar um nível de resposta hipnótica do sujeito, que foi desenvolvido como uma versão de grupo da Stanford Hypnotic Susceptibility Scale, Form C (SHSS:C) ${ }^{12}$.

Podem ser experimentadas alterações seguidas ao tratamento hipnótico, por indivíduos com respostas baixas nas escalas-teste. A remoção de defesas contra as respostas hipnóticas, do poder da relação terapêutica ou das informações sobre o objetivo das sugestões e exercícios pode ser a causa para essas mudanças. Durante a hipnose, as sugestões transmitidas produzem inúmeras respostas em diferentes pessoas, mas um ponto fundamental é como predizer que um indivíduo responderá as sugestões propostas ${ }^{13}$.

De acordo com Ferreira (2003), a sugestionabilidade hipnótica não se correlaciona com as características personológicas de um indivíduo. Similarmente ao autor, Nordenstrom e cols. (2002) não acharam correlação entre a sugestionabilidade hipnótica e o "Big Five", que é um teste de personalidade que utiliza os cinco grandes fatores da personalidade: intelecto/abertura, consciência, neuroticismo (instabilidade emocional), agradabilidade e extroversão.

O Inventário Fatorial de Personalidade - Versão Reduzida (IFP - R) é um instrumento que visa avaliar o indivíduo normal em treze fatores de personalida-

\footnotetext{
${ }^{8}$ FERREIRA, 2003.

${ }^{9}$ BENHAM, SMITH, \& NASH, 2002.

${ }^{10}$ KALLIO, \& IHAMUOTILA, 1999.

${ }^{11}$ BENHAM, SMITH, \& NASH, 2002.

${ }^{12}$ NORDENSTROM, COUNCIL, \& MEIER, 2002.

${ }^{13}$ FERREIRA, 2003.
} 
de: Assistência, Intracepção, Afago, Deferência, Afiliação, Dominância, Desempenho, Exibição, Agressão, Ordem, Persistência, Mudança e Autonomia, podendo ser aplicado individual ou coletivamente em adultos e jovens com segundo grau completo. O fator Assistência representa o construto que demonstra os desejos e sentimentos de piedade, ternura e compaixão; Intracepção expressa a dominação pela procura da felicidade, fantasia e imaginação; Afago, a busca de apoio e proteção; Deferência, o respeito, admiração e reverência; Afiliação apresenta o dar e receber de amigos o afeto; Dominância, os sentimentos de autoconfiança e o desejo de controlar e influenciar o comportamento dos outros; Desempenho, ambição e empenho; Exibição expressa o desejo de impressionar, a vaidade; Agressão, a raiva, irritação e ódio; Ordem, a organização, equilíbrio e precisão; Persistência, a tendência de terminar um trabalho iniciado por mais difícil que pareça; Mudança, a tendência de desligar-se do que é rotineiro e fixo; e Autonomia, resistir à coerção e oposição, o gostar de agir independentemente. Também possui uma escala de Desejabilidade Social e outra de Mentira ou Validade, que avaliam o nível de veracidade das respostas. A escala de Validade verifica se o indivíduo respondeu ao acaso, ou adequadamente, isto é, se ele respondeu sem atenção, mentiu ou não entendeu a tarefa. A escala de Desejabilidade Social verifica se o indivíduo respondeu segundo as expectativas dos outros e não segundo suas próprias necessidades ${ }^{14}$. O teste pode ser aplicado individualmente ou a grupos de até 35 sujeitos, desde que haja acomodações suficientes e adequadas.

O IFP - R trata-se de uma revisão do IFP (primeira versão validada no Brasil em 1996) que é baseado no Edwards Personal Preference Schedule (EPPS), desenvolvido por Allen L. Edwards em 1953 e revisto em 1959. A validação e redução do IFP-R foi realizada com 3.806 sujeitos (76,9\% de homens e $23,1 \%$ de mulheres), em mais de quatro Estados, sendo a maioria estudantes universitários (78\%). O teste possui 130 itens que avaliam personalidade incluindo desejabilidade social e validade (para verificar quem o leu atentamente). O IFP-R, portanto, é o resultado de uma revalidação atualizada da adaptação realizada em 1996. Baseado na teoria das necessidades básicas formulada por Henry Murray em 1938, tornou-se ainda menos cansativo para quem o responde pela redução de 25 itens do IFP original brasileiro e 100 itens menos que o EPPS. O teste pode ser utilizado para pesquisas, além de um instrumento para obter-se uma rápida e adequada medida das variáveis da personalidade normal ${ }^{15}$.

\footnotetext{
${ }^{14}$ PASQUALI, ARAÚJO \& TRÓCCOLI, 1999.

${ }^{15}$ PASQUALI, ARAÚJO \& TRÓCCOLI, 1999.
}

Univ. Ci. Saúde, Brasília, v. 3, n. 2, p. 191-205, jul./dez. 2005 


\section{Metodologia}

O objetivo desta pesquisa é verificar se há relação entre os fatores do Inventário Fatorial de Personalidade (IFP-R) e os doze itens da Escala de Grupo Harvard de Susceptibilidade Hipnótica, forma A (HGSHS:A). Porém, como esta escala não está validada no Brasil, uma etapa preliminar buscou verificar a viabilidade de sua aplicação, comparando os dados com outros países.

\section{Participantes}

A coleta de dados foi realizada primeiramente com uma sessão piloto, que serviu para fazer os devidos ajustes de procedimento. Em seguida, foram utilizados 33 participantes voluntários, divididos em três sessões com média de 11 participantes cada. Os participantes foram convidados através de contato pessoal.

Dezessete partipantes são do sexo masculino (18 e 44 anos) e dezesseis do sexo feminino (18 e 27 anos). A idade média dos participantes ficou em 23 anos. Os participantes são provenientes de vários cursos e de vários semestres, inclusive formados. Todos concordaram com o termo de consentimento livre e esclarecido, previamente aprovado pelo Comitê de Ética do UniCEUB antes do início da pesquisa.

\section{Procedimento}

Primeiramente, o segundo autor leu as informações preliminares do experimento para esclarecimentos. Em seguida, foram entregues aos participantes o termo de consentimento livre e esclarecido que foi lido em voz alta. Foi enfatizado que o participante poderia deixar o experimento em qualquer momento, caso o desejasse.

A pesquisa foi dividida em duas fases: na primeira, os participantes ouviram um CD de áudio contendo o procedimento hipnótico, seguindo o modelo padronizado que consta no manual original da escala de suscetibilidade hipnótica Harvard Group Scale of Hypnotic Susceptibility, Form A (HGSHS:A) ${ }^{15}$. O manual foi traduzido para a língua portuguesa, seguindo a versão original, bem como: as informações preliminares, o Livreto de Respostas, a indução e sugestões incluídas na HGSHS:A. O CD de áudio com as instruções também foi gravado pelo segundo autor utilizando equipamento semi-profissional, seguindo a cronometragem adotada pelo manual original.

${ }^{15}$ SHOR \& ORNE, 1962. 
As instruções se iniciaram com algumas recomendações para estabelecer o rapport (com duração de sete minutos), onde através de uma conversa preliminar o experimentador fez as considerações iniciais, como orientações sobre a postura, hipnose e sobre o que iria se suceder, assumindo-se que os participantes foram notificados da testagem de hipnose e que suas presenças seriam uma aceitação em serem hipnotizados. Posteriormente, receberam os procedimentos principais (com duração de 42 minutos e 15 segundos) através do $\mathrm{CD}$, que incluem os itens: (1) Caindo a Cabeça, (2) Fechamento dos Olhos, (3) Abaixamento da Mão Esquerda, (4) Imobilização do Braço Direito, (5) Entrelaçamento dos Dedos, (6) Rigidez do Braço Esquerdo, (7) Movimento das Mãos Juntas, (8) Inibição da Comunicação, (9) Alucinação do Mosquito, (10) Catalepsia do Olho, (11) Sugestão Pós-Hipnótica (Tocando o Tornozelo Esquerdo) e (12) Amnésia. Após o procedimento completo, os participantes responderam o Livreto de Respostas seguindo as instruções do experimentador.

$\mathrm{Na}$ segunda fase, os participantes responderam o Inventário Fatorial de Personalidade - Versão Reduzida (IFP-R), logo após a indução hipnótica. Os fatores de personalidade medidos foram: Assistência, Intracepção, Afago, Deferência, Afiliação, Dominância, Desempenho, Exibição, Agressão, Ordem, Persistência, Mudança e Autonomia. Para aplicação e correção foram seguidas as instruções do manual do IFP-R ${ }^{16}$.

A aplicação desse teste, bem como o de hipnose, foi conduzida de forma coletiva, em sala de aula no Centro Universitário de Brasília.

\section{Pontuação}

O escore das respostas do Livreto da HGSHS:A seguiu o procedimento descrito por Shor e Orne (1962). Os participantes receberam 1 como pontuação caso tivessem marcado item A (indicando uma mudança comportamental experienciada para uma sugestão dada) e 0 se o item $\mathrm{B}$ tivesse sido marcado (indicando que a mudança comportamental não foi experienciada). Os dados utilizados para a pontuação geral de suscetibilidade hipnótica foram obtidos dos itens 1 a 12, não levando em consideração o item 13 (de Amnésia), os itens objetivos e os subjetivos. Estes itens serão analisados posteriormente, seguindo orientações da literatura.

Para o inventário de personalidade, foi obtido o escore bruto de cada um dos quinze fatores somando-se as respostas dadas aos itens correspondentes a cada necessidade, de acordo com o manual.

${ }^{16}$ PASQUALI, ARAÚJO \& TRÓCCOLI, 1999.

Univ. Ci. Saúde, Brasília, v. 3, n. 2, p. 191-205, jul./dez. 2005 


\section{Resultados}

Os dados foram tratados de duas formas: 1) comparação da tradução da escala HGSHS:A, para fins de validação da mesma na população brasileira; 2) comparação do grau de responsividade hipnótica com os fatores personológicos do Inventário Fatorial de Personalidade (IFP-R).

Os resultados apresentaram que os 33 obtiveram uma hipnotizabilidade média de 6,58 (d.p.=2,44) (numa escala que varia de 0 (para pouco susceptível) a 12 (muito susceptível). A porcentagem de responsividade ficou em 54,92 (d.p.=24,57). Na Figura 1 foram mostrados as porcentagens de responsividade dos sujeitos da amostra $(\mathrm{N}=33)$ de acordo com cada item da tradução da escala de susceptibilidade hipnótica HGSHS:A.

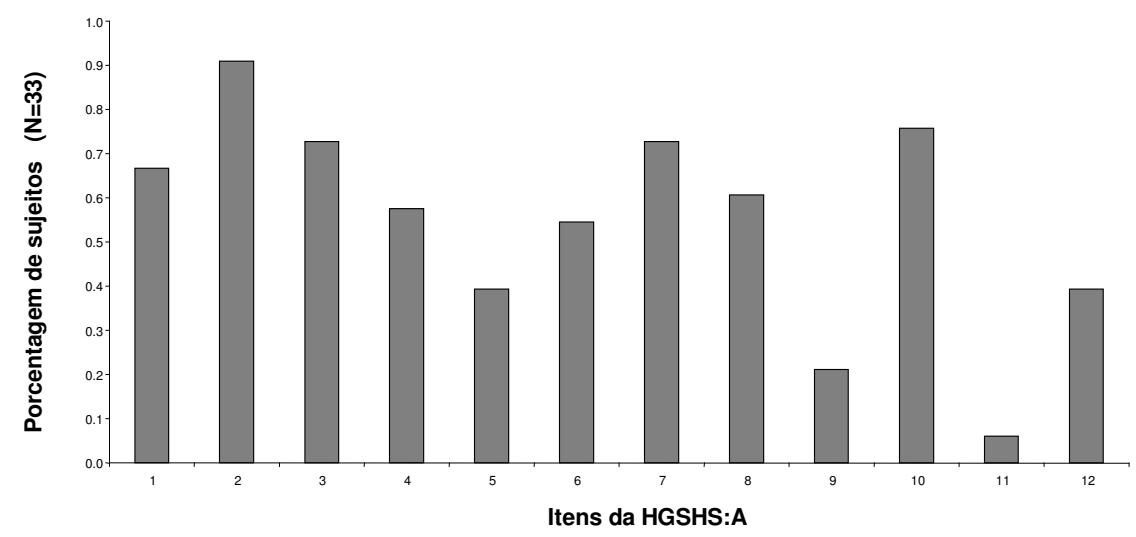

Figura 1 - Índice da porcentagem de sujeitos brasileiros $(\mathrm{N}=33)$ que responderam aos 12 itens da tradução da escala HGSHS:A.

Na tabela 1 temos as comparações entre as médias de responsividade hipnótica e os escores brutos do Brasil com mais oito países de referências. 
Tabela 1. Média e desvio-padrão dos valores de responsividade hipnótica para nove países. $\mathrm{O}$ escore, e seu desvio-padrão, refere-se aos valores que vão de 0 (nada susceptível) a 12 (totalmente susceptível) do total da amostra.

\begin{tabular}{cccccc}
\hline Países & $\begin{array}{c}\mathrm{N}^{\text {o.de }} \\
\text { sujeitos }\end{array}$ & Média & $\begin{array}{c}\text { Desvio } \\
\text { padrão }\end{array}$ & Escore & $\begin{array}{c}\text { Desvio } \\
\text { padrão }\end{array}$ \\
\hline Brasil & 33 & 54,92 & 24,574 & 6,58 & 2,44 \\
Suécia & 291 & 56,42 & 20,756 & $*$ & $*$ \\
Itália & 376 & 53,08 & 12,810 & $*$ & $*$ \\
Finlândia & 285 & 60,42 & 20,161 & 7,26 & 2,61 \\
Dinamarca & 376 & 63,67 & 21,339 & $*$ & $*$ \\
Espanha & 374 & 59,42 & 16,121 & 7,13 & 2,61 \\
Alemanha & 230 & 56,17 & 16,236 & 6,5 & 2,43 \\
Austrália & 1.994 & 45,42 & 17,312 & 5,45 & 2,95 \\
EUA & 132 & 62,75 & 17,457 & 7,39 & 3,04 \\
\hline
\end{tabular}

* Dados não encontrados na literatura.

A Tabela 2 mostra os dados já coletados em alguns países, de acordo com Kallil e Ihamuotila (1999) e Bergman, Trenter e Kallil (2003) comparados com a atual amostra brasileira $(\mathrm{N}=33)$. Cada um dos 12 itens foi comparado entre os países quanto à porcentagem de respondentes.

Foram calculados, através do software estatístico SPSS 13.0 (versão demonstrativa), as correlações entre as escalas HGSS:A da amostra brasileira e de oito países de referências, como mostrados na tabela 3. Mesmo com um número pequeno de sujeitos $(\mathrm{N}=33)$, houve correlações significativas entre a amostra brasileira e as dos demais países, como a Suécia, Finlândia, Espanha, Alemanha e Austrália $(\mathrm{p}<0,01)$. 
Tabela 2. Porcentagem de respondentes para cada item da escala HGSHS:A no Brasil e países de comparação. Em parênteses estão representadas as posições relativas dos itens mais respondidos aos menos respondidos pela amostra.

\begin{tabular}{|c|c|c|c|c|c|c|c|c|c|}
\hline $\begin{array}{c}\text { HGSHS:A } \\
\text { (itens individuais) }\end{array}$ & $\begin{array}{c}\text { Brasil } \\
(\mathrm{N}=33)\end{array}$ & $\begin{array}{l}\text { Suécia } \\
(\mathrm{N}=291)\end{array}$ & $\begin{array}{c}\text { Itália } \\
(\mathrm{N}=376)\end{array}$ & $\begin{array}{l}\text { Finlândia } \\
(\mathrm{N}=285)\end{array}$ & $\begin{array}{c}\text { Dinamarca } \\
(\mathrm{N}=376)\end{array}$ & $\begin{array}{l}\text { Alemanha } \\
(\mathrm{N}=374)\end{array}$ & $\begin{array}{l}\text { Espanha } \\
(\mathrm{N}=220)\end{array}$ & $\begin{array}{l}\text { Austrália } \\
(\mathrm{N}=220)\end{array}$ & $\begin{array}{c}\text { EUA } \\
(N=132)\end{array}$ \\
\hline 1. Caindo a Cabeça & $67(5)$ & $70(3)$ & $70(1)$ & $84(3)$ & $86(1)$ & $73(3,5)$ & $73(3)$ & $61(3)$ & $86(2,5)$ \\
\hline $\begin{array}{l}\text { 2. Fechamento dos } \\
\text { Olhos }\end{array}$ & $91(1)$ & $76(1)$ & $62(4)$ & $86(2)$ & $48(10)$ & $73(3,5)$ & $64(6)$ & $57(4)$ & $74(4)$ \\
\hline $\begin{array}{l}\text { 3. Abaixamento da } \\
\text { Mão Esquerda }\end{array}$ & $73(3,5)$ & $66(4)$ & $56(6,5)$ & $89(1)$ & $75(3,5)$ & $83(1)$ & $60(7)$ & $71(1,5)$ & $89(1)$ \\
\hline $\begin{array}{l}\text { 4. Imobilização do } \\
\text { Braço Direito }\end{array}$ & $58(7)$ & $61(8)$ & $55(8)$ & 43(10) & 72(7) & $52(6,5)$ & $58(9)$ & $36(9)$ & $48(10,5)$ \\
\hline $\begin{array}{l}\text { 5. Travamento dos } \\
\text { Dedos }\end{array}$ & $39(9,5)$ & $74(2)$ & $60(5)$ & $66(5)$ & $76(5)$ & $57(5)$ & $67(5)$ & $53(5)$ & $67(5)$ \\
\hline $\begin{array}{l}\text { 6. Rigidez do Braço } \\
\text { Esquerdo }\end{array}$ & $55(8)$ & $65(5,5)$ & $63(3)$ & $53(7,5)$ & $75(3,5)$ & $52(6,5)$ & $69(4)$ & $41(7)$ & $57(6)$ \\
\hline $\begin{array}{l}\text { 7. Movendo as Mãos } \\
\text { Juntas }\end{array}$ & $73(3,5)$ & 64(7) & 64(2) & 78(4) & $78(2)$ & $74(2)$ & $79(1)$ & $71(1,5)$ & $86(2,5)$ \\
\hline $\begin{array}{l}\text { 8. Inibição da } \\
\text { Comunicação }\end{array}$ & $61(6)$ & $56(9)$ & $48(9)$ & $56(6)$ & $73(6)$ & $49(8)$ & $74(2)$ & $42(6)$ & $50(9)$ \\
\hline $\begin{array}{l}\text { 9. Esperiência do } \\
\text { Mosquito }\end{array}$ & $21(11)$ & $14(12)$ & $28(12)$ & $28(12)$ & $38(11)$ & $47(9,5)$ & $29(11,5)$ & $25(11)$ & $56(7,5)$ \\
\hline $\begin{array}{l}\text { 10. Catalepsia do } \\
\text { Olho }\end{array}$ & $76(2)$ & $51(10)$ & $40(10)$ & $52(9)$ & $61(9)$ & $47(9,5)$ & $59(8)$ & $38(8)$ & $56(7,5)$ \\
\hline $\begin{array}{l}\text { 11. Sugestão Pós- } \\
\text { Hipnótica (Tocando o } \\
\text { Tornozelo Esquerdo) }\end{array}$ & $6(12)$ & $15(11)$ & $35(11)$ & $37(11)$ & $11(12)$ & $31(12)$ & $29(11,5)$ & 17(12) & $36(12)$ \\
\hline $\begin{array}{l}\text { 12. Amnésia Pós- } \\
\text { Hipnótica } \\
\text { (Esquecimento } \\
\text { Temporário) }\end{array}$ & $39(9,5)$ & $65(5,5)$ & $56(6,5)$ & $53(7.5)$ & 71(8) & $36(11)$ & $52(10)$ & $33(10)$ & $48(10,5)$ \\
\hline
\end{tabular}


Tabela 3. Correlações entre as posições das escalas HGSS:A entre a amostra brasileira e oito países de comparação.

\begin{tabular}{|c|c|c|c|c|c|c|c|c|}
\hline - & Suécia & Itália & Finlândia & Dinamarca & Espanha & Alemanha & Austrália & EUA \\
\hline Brasil & $\begin{array}{l}.736 \\
(* *)\end{array}$ & $\begin{array}{c}.594 \\
(*)\end{array}$ & $\begin{array}{l}.745 \\
(* *)\end{array}$ & $\begin{array}{l}.577 \\
(*)\end{array}$ & $\begin{array}{l}.754 \\
(* *)\end{array}$ & $\begin{array}{l}.733 \\
(* *)\end{array}$ & $\begin{array}{l}.745 \\
(* *)\end{array}$ & $\begin{array}{c}.640 \\
(*)\end{array}$ \\
\hline Suécia & & $\begin{array}{l}.903- \\
(* *)\end{array}$ & $\begin{array}{l}.763 \\
(* *)\end{array}$ & $\begin{array}{l}.802 \\
(* *)\end{array}$ & $\begin{array}{l}.848 \\
(* *)\end{array}$ & $\begin{array}{c}.599 \\
(*)\end{array}$ & $\begin{array}{l}.736 \\
(* *)\end{array}$ & .560 \\
\hline Itália & & & $\begin{array}{c}.76 \\
8(* *)\end{array}$ & $\begin{array}{l}.747 \\
(* *)\end{array}$ & $\begin{array}{l}.816 \\
(* *)\end{array}$ & $\begin{array}{c}.632 \\
(*)\end{array}$ & $\begin{array}{l}.744 \\
(* *)\end{array}$ & $\begin{array}{c}.623 \\
(*)\end{array}$ \\
\hline Finlândia & & & & .535 & $\begin{array}{c}.696 \\
(*)\end{array}$ & $\begin{array}{l}.878 \\
(* *)\end{array}$ & $\begin{array}{l}.933 \\
(* *)\end{array}$ & $\begin{array}{l}.875 \\
(* *)\end{array}$ \\
\hline Dinamarca & & & & & $\begin{array}{l}.839 \\
(* *)\end{array}$ & .517 & $\begin{array}{c}.666 \\
(*)\end{array}$ & .540 \\
\hline Espanha & & & & & & $\begin{array}{c}.603 \\
(*)\end{array}$ & $\begin{array}{l}.762 \\
(* *)\end{array}$ & .575 \\
\hline Alemanha & & & & & & & $\begin{array}{l}.941 \\
(* *)\end{array}$ & $\begin{array}{l}.954 \\
(* *)\end{array}$ \\
\hline Austrália & & & & & & & & $\begin{array}{l}.942 \\
(* *)\end{array}$ \\
\hline EUA & & & & & & & & 1 \\
\hline
\end{tabular}

** A correlação é significativa no nível 0,01 .

* A correlação é significativa no nível 0,05 .

Tendo observado fortes correlações entre a tradução da escala HGSHS:A, na segunda parte da pesquisa pudemos comparar a pontuação obtida na escala de susceptibilidade hipnótica com a pontuação obtida no inventário de personalidade (IFP-R). Houve uma correlação positiva significativa entre o fator Persistência e a responsividade à hipnose (Pearson $=0,525 ; \mathrm{p}<0,01)$. Os valores estão mostrados na tabela 4.

A regressão com a análise de variância (ANOVA) mostra ainda uma correlação negativa entre o fator Autonomia ( $\mathrm{F}=11,777 ; \mathrm{p}=0,002)$, além da correlação positiva encontrada para o fator Persistência $(\mathrm{F}=10,193 ; \mathrm{p}=0,000)$. Os valores de $\mathrm{t}$ para os fatores são -2,552 ( $\mathrm{p}<0,01)$ e 4,233 ( $<<0,001)$, respectivamente (ver tabela 5).

Univ. Ci. Saúde, Brasília, v. 3, n. 2, p. 191-205, jul./dez. 2005 
Tabela 4. Correlação entre a pontuação na HGSHS:A e os fatores de personalidade IFP-R para os sujeitos da amostra brasileira $(\mathrm{N}=33)$.

\begin{tabular}{|c|c|c|}
\hline \multirow{2}{*}{ Fatores IFP-R } & \multicolumn{2}{|c|}{ Pontuação na escala HGSHS:A } \\
\hline & $\begin{array}{l}\text { Correlação de } \\
\text { Pearson }\end{array}$ & Significância \\
\hline Assistência & $-0,076$ & 0,673 \\
\hline Intracepção & 0,127 & 0,481 \\
\hline Afago & 0,163 & 0,365 \\
\hline Deferência & 0,062 & 0,733 \\
\hline Afiliação & 0,189 & 0,291 \\
\hline Dominância & 0,097 & 0,591 \\
\hline Desempenho & 0,312 & 0,077 \\
\hline Exibição & 0,043 & 0,813 \\
\hline Agressão & 0,164 & 0,362 \\
\hline Ordem & 0,319 & 0,070 \\
\hline Persistência & $0,525(* *)$ & 0,002 \\
\hline Mudança & $-0,136$ & 0,449 \\
\hline Autonomia & $-0,221$ & 0,216 \\
\hline
\end{tabular}

A regressão com a análise de variância (ANOVA) mostra ainda uma correlação negativa entre o fator Autonomia $(\mathrm{F}=11,777 ; \mathrm{p}=0,002)$, além da correlação positiva encontrada para o fator Persistência $(\mathrm{F}=10,193 ; \mathrm{p}=0,000)$. Os valores de t para os fatores são $-2,552(\mathrm{p}<0,01)$ e 4,233 ( $\mathrm{p}<0,001)$, respectivamente (ver tabela 5). 
Características personológicas da susceptibilidade hipnótica

Tabela 5. Variáveis excluídas dos fatores de personalidade (variável independente) e a pontuação da escala de susceptibilidade (variável dependente, c).

\begin{tabular}{|c|c|c|c|c|c|c|}
\hline Modelo & & Beta In & $\mathrm{t}$ & Sig. & $\begin{array}{c}\text { Correlação } \\
\text { Parcial }\end{array}$ & $\begin{array}{l}\text { Estatística de } \\
\text { Colinearidade }\end{array}$ \\
\hline \multirow[t]{12}{*}{1} & assistência & $-0,117(a)$ & $-0,760$ & 0,453 & $-0,137$ & 0,994 \\
\hline & intracepção & $-0,024(a)$ & $-0,146$ & 0,885 & $-0,027$ & 0,920 \\
\hline & Afago & $-0,059$ (a) & $-0,349$ & 0,730 & $-0,064$ & 0,836 \\
\hline & deferência & $-0,179$ (a) & $-1,076$ & 0,291 & $-0,193$ & 0,837 \\
\hline & afiliação & $-0,055(a)$ & $-0,317$ & 0,754 & $-0,058$ & 0,802 \\
\hline & dominância & $-0,184(a)$ & $-1,073$ & 0,292 & $-0,192$ & 0,787 \\
\hline & desempenho & $-0,030(a)$ & $-0,149$ & 0,883 & $-0,027$ & 0,605 \\
\hline & exibição & $-0,070$ (a) & $-0,443$ & 0,661 & $-0,081$ & 0,956 \\
\hline & agressão & 0,048 (a) & 0,302 & 0,765 & 0,055 & 0,949 \\
\hline & ordem & $0,110(\mathrm{a})$ & 0,637 & 0,529 & 0,116 & 0,806 \\
\hline & mudança & $-0,200$ (a) & $-1,313$ & 0,199 & $-0,233$ & 0,987 \\
\hline & autonomia & $-0,371(a)$ & $-2,552$ & 0,016 & $-0,422$ & 0,941 \\
\hline \multirow[t]{11}{*}{2} & assistência & $-0,156(b)$ & $-1,102$ & 0,279 & $-0,200$ & 0,984 \\
\hline & intracepção & $0,086(b)$ & 0,555 & 0,583 & 0,102 & 0,850 \\
\hline & afago & $-0,099(b)$ & $-0,631$ & 0,533 & $-0,116$ & 0,828 \\
\hline & deferência & $-0,166(b)$ & $-1,082$ & 0,288 & $-0,197$ & 0,836 \\
\hline & afiliação & $-0,165(b)$ & $-1,015$ & 0,319 & $-0,185$ & 0,753 \\
\hline & dominância & $-0,038(b)$ & $-0,216$ & 0,830 & $-0,040$ & 0,676 \\
\hline & desempenho & 0,042 (b) & 0,225 & 0,824 & 0,042 & 0,591 \\
\hline & exibição & 0,009 (b) & 0,062 & 0,951 & 0,011 & 0,912 \\
\hline & agressão & $0,164(b)$ & 1,090 & 0,285 & 0,198 & 0,876 \\
\hline & ordem & 0,197 (b) & 1,244 & 0,224 & 0,225 & 0,774 \\
\hline & mudança & $-0,052$ (b) & $-0,325$ & 0,747 & $-0,060$ & 0,799 \\
\hline
\end{tabular}

a Preditores no Modelo: (Constante), persistência

b Preditores no Modelo: (Constante), persistência, autonomia

c Variável Dependente: Pontuação na HGSHS:A

Univ. Ci. Saúde, Brasília, v. 3, n. 2, p. 191-205, jul./dez. 2005 


\section{Discussão e Conclusão}

Os dados mostraram que, mesmo com poucos sujeitos para validar um instrumento psicométrico, medida psicológica para a população brasileira, a tradução e a aplicação da escala HGSHS:A foi bem sucedida. As fortes correlações encontradas com as escalas traduzidas e validadas nos países de referências sugerem que esta escala será, em breve, validada também no Brasil. Uma escala devidamente validada auxilia psicólogos e outros profissionais de saúde a medir corretamente a susceptibilidade hipnótica de pacientes em consultórios e em pesquisas cognitivas e comportamentais.

A média da amostra pesquisada $(54,92)$ está muito próxima de outros países, como a Itália, Suécia e Alemanha. Porém, com um número reduzido de sujeitos (N=33), o desvio-padrão alto $(24,57)$, conforme tabela 1 , mostra que ainda há fatores da variabilidade individual envolvida. Espera-se que, com um número maior de sujeitos, este desvio-padrão venha a abaixar. Quando o escore (na mesma tabela) é comparado, nossos dados são praticamente idênticos aos obtidos na Alemanha, que utilizou 230 sujeitos.

Na tabela 2, onde os itens foram classificados como (1) para os mais respondidos pelos participantes, a (12) para os menos respondidos, podemos observar apenas uma pequena diferença com a amostra brasileira com as dos países de comparação. O item Catalepsia do Olho foi o segundo mais respondido pelos participantes, enquanto que em outros países este item foi o oitavo ou décimo na ordem de responsividade. Em contrapartida, o item Caindo a Cabeça teve uma responsividade mais baixa em nossa amostra (ver dados na tabela 2). Porém, as correlações encontradas na tabela 3 sugerem que a responsividade ao item não foi relevante no conjunto dos dados. A correlação da amostra brasileira foi significativa com todos os países de comparação, que já possuem a escala validada.

Esta primeira etapa de validação da escala é muito importante, pois nos diz se, de fato, a escala está medindo o que se propõe. A segunda etapa busca, de fato, responder se há características de personalidade que possam estar relacionadas com a alta ou baixa susceptibilidade à hipnose.

Nas tabelas 4 e 5 podemos constatar que os fatores Persistência e Autonomia estão relacionados com a susceptibilidade. Quanto maior a pontuação na escala de HGSHS:A, maior o fator da Persistência e menor o fator da Autonomia. Mesmo com um número pequeno de sujeitos, estes fatores puderam ser observados como correlacionados com a susceptibilidade hipnótica. Porém, não se pode assegurar que outros fatores como Mudança, Desempenho ou Ordem não este- 
jam. Sugerimos, no entanto, a necessidade de se continuar a averiguar se outros fatores também poderão estar envolvidos.

A necessidade de se ter uma escala de susceptibilidade hipnótica validada está aqui evidenciada. Para pesquisas futuras, propõe-se que outros instrumentos de medida da personalidade humana possa ser aplicada, e que um número maior de sujeitos venha a ser recrutado.

\section{Referências}

BENHAM, G.; SMITH, N.; NASH, M. R. Hypnotic Susceptibility Scales: Are the Mean Scores Increasing? The International Journal of Clinical and Experimental Hypnosis, 50, p. 5-17, 2002.

BERGMAN, M.; TRENTER, E.; KALLIO, S. Swedish norms for the Harvard Group Scale of Hypnotic Susceptibility, Form A. International Journal of Clinical and Experimental Hypnosis, Vol. 51, No. 4, p. 348-356, 2003.

FERREIRA, M. V. C. Hipnose na Prática Clinicanegrito São Paulo: Atheneu, 2003.

KALLIO, S. P. I.; IHAMUOTILA, M. J. Finnish Norms for the Harvard Group Scale of Hypnotic Susceptibility, Form A, 1999. Disponível em: <http://users.utu.fi/shakal/ HGSHSA_Finnish.pdf> Acesso em: 15 maio 2004.

KIRSCH, I. \& BRAFFMAN, W. Imaginative Suggestibility and Hypnotizability. Current Directions in Psychological Science, 10, p. 57-61, 2001.

NEUBERN, M. S. Hipnose e Psicologia Clínica: Problemas Clínicos, Epistemológicos e Históricos. Universitas Ciências da Saúde, Vol 2, No. 1, p. 39-55, 2004.

NORDENSTROM, B. K.; COUNCIL, J. R.; MEIER, B. P. The "Big Five" and Hypnotic Suggestibility. The International Journal of Clinical and Experimental Hypnosis, 50, p. 276-281, 2002.

PASCALIS, V. et al. Suggestion and Suggestibility: Theory and Research. Contemporary Hypnosis, 19, p. 139-145, 2002.

PASQUALI, L.; ARAÚJO, R. M.; TROCCOLI, B. T. Manual Técnico e de AplicaçãoInventário Fatorial de Personalidade - Versão ReduzidanegritoBrasília: LABPAM, 1999.

RHUE, J. W.; LYNN, S. J. \& KIRSCH, I. Handbook of Clinical Hypnosis. American Psychological Association. Washington: DC, 1997.

SHOR, R. E., \& ORNE, E. C. Harvard Group Scale of Hypnotic Susceptibility, Form A. Palo Alto, CA: Consulting Psychologists Press, 1962

SHOR, R. E., \& ORNE, E. C. Norms on the Harvard Group scale of Hypnotic Susceptibility, Form A. International Journal of Clinical and Experimental Hypnosis, 11, 39-47, 1963. 


\begin{tabular}{|}
\hline \\
Envie suas publicações para o Conselho Editorial \\
da revista Universitas - Ciências da Saúde. \\
Endereço para envio: \\
SEPN 707/907, Campus do UniCEUB \\
70790-075 Brasília-DF \\
Fone: (61) 3340-1397 \\
universitas.saude@ uniceub.br \\
Verifique as normas de submissão no final deste número
\end{tabular}

